IN DEFENSE OF COMMON SENSE IN ENTREPRENEURSHIP

THEORY:

BEYOND PHILOSOPHICAL EXTREMITIES AND LINGUISTIC ABUSES

\begin{tabular}{|r|l|}
\hline Journal: & Academy of Management Review \\
\hline Manuscript ID & AMR-2017-0169-Dialogue \\
\hline Manuscript Type: & Dialogue \\
\hline Keywords: & $\begin{array}{l}\text { Entrepreneurship, Philosophy (Epistemology, Ontology), Philosophy of } \\
\text { Science, Economics }\end{array}$ \\
\hline Abstract: & \\
\hline \multicolumn{2}{|r}{} \\
\hline
\end{tabular}




\title{
IN DEFENSE OF COMMON SENSE IN ENTREPRENEURSHIP THEORY: BEYOND PHILOSOPHICAL EXTREMITIES AND LINGUISTIC ABUSES
}

\author{
STRATOS RAMOGLOU \\ University of Southampton \\ Highfield Campus (28/2015) \\ SO17 1BJ Hampshire \\ United Kingdom \\ s.ramoglou@soton.ac.uk
}

\section{ERIC W. K. TSANG}

University of Texas at Dallas

800 W Campbell Rd., SM43

Richardson, TX 75080-3021

USA

ewktsang@utdallas.edu 
Whether entrepreneurial opportunities are discovered or created is a long-standing dilemma in the study of entrepreneurship. In our recent article (Ramoglou \& Tsang, 2016 [R\&T hereafter]), we framed this dilemma as false. Opportunities are neither discovered nor created. They are objectively existing propensities to be creatively actualized.

Central to our analysis has been the ontological rectification of the mode of existence of opportunities. Whereas opportunities are systematically mistreated as actualized entities triggering successful entrepreneurial action when empirically discovered (Kirzner, 1979; Shane \& Venkataraman, 2000), we clarified that they exist as the propensity of market demand to be actualized into profits through the introduction of novel products or services. Opportunities exist as the non-actualized market conditions making possible the emergence of desirable outcomes. They exist analogously to the planted seed's propensity to manifest empirically into a flowernot akin to the flower itself or the means of its actualization. We also argued that though opportunities are subjectively imagined and creatively actualized, contrary to Alvarez and Barney's (2007, 2010) claim, they are not created. Creative entrepreneurial agency is not constitutive of the existence of opportunities but is part of the actualization process. Similarly, farming processes stimulate-yet do not create — the seed's potential.

The actualization approach overcomes the discovered versus created dilemma in a manner that brings center-stage the ontological uncertainties of enterprise (McMullen \& Shepherd, 2006). We know that opportunities exist in the economic landscape, but we don't know when and where they exist or whether they will be successfully actualized. We know when imagined opportunities correspond to real ones only after their empirical manifestation into profits.

The actualization framework brings conceptual clarity and order in a discourse characterized by growing confusion (Crawford, Dimov \& McKelvey, 2016; Davidsson, 2015). Alvarez, 
Barney, McBride and Wuebker (2017) (ABMW), Berglund and Korsgaard (2017) (B\&K), and Foss and Klein (2017) (F\&K) take issue with several parts of R\&T. The comments provide us a valuable opportunity to further advance the discourse into the very intellectual foundation of entrepreneurship theory. We refute critiques, caution against the philosophical extremities of empiricist and idealist assumptions, and debunk "opportunity creation" as a philosophically and linguistically problematic approach. We show that the actualization approach embraces common sense and is free from the fatal flaws associated with the discovery and creation approaches.

\section{REFUTING CRITIQUES}

\section{Keeping the Concept of Opportunity but Refining its Meaning}

F\&K acknowledge that our account of opportunities offers an improvement over competing ones, but question the use of "the nebulous and elusive concept of opportunities," because what "we mean are expectations, plans, efforts, and outcomes" (\#). F\&K are right to say so if by "we" they mean "some academics." Academic uses of "opportunity" have largely severed ties with its everyday meaning, turning it into a nebulous and elusive concept indeed. However, to dispense with the word is "to change the focus of the conversation rather than tackle the difficult questions presented by the opportunity concept" (Wood, 2017: 21).

A more sensible approach is to keep the word but make its meaning congruent with everyday understandings. Entrepreneurs do not have difficulties with the everyday use of the opportunity concept. They know that opportunities do not refer to "expectations, plans, efforts and outcomes," but to the conditions making possible the outcomes that motivate entrepreneurial efforts and correspondingly making expectations plausible and plans meaningful. After all, "opportunity" is not a metaphor, as maintained by F\&K and Kirzner (1999). It is a word drawn from the native language of entrepreneurs (Wood, 2017), but inadvertently entangled in 
misleading metaphors-from Kirzner (1979) onwards (R\&T: 416). Dropping the word "opportunity" will only create a higher wall between the ivory tower and practitioners. The fact is, even if the word disappears from academic literatures, the word and its equivalent in different languages will stay in daily usage. Of course, F\&K and Wood (2017) are correct to remark that entrepreneurs do not explicitly use the language of "propensities" or "nonopportunities." Yet what matters is that this theoretical language is consistent with their understandings. Similarly, the actions of basketball players are consistent with the laws of physics notwithstanding whether the athletes themselves can use theoretical physics to explain the movement of the ball.

F\&K also criticize the propensity conceptualization as "unnecessarily cumbersome" (\#). It is true that the conclusions of abstract theoretical analyses might be intellectually demanding; theoretical physicists use some truly difficult concepts and principles. But complexity has no bearing on truthfulness. Operationalizations probably offer the simplest possible treatment of the “opportunity" construct (see Davidsson, 2017), but the simpler they are the more distanced they also become from realistic understandings of the entrepreneurial phenomenon (Ramoglou \& Tsang, 2017). We submit that the propensity conceptualization offers the least demanding theory necessary for doing justice to the ontological complexities of the phenomenon.

\section{The Tautology Critique}

Is the actualization approach tautological? ABWM (p. \#) comment that it is. With sufficient distortion, it is always the case that "a theory can be restated in such a way as to make it tautological" (Barney, 2001: 42). Consider the statement: "ex post profits (or losses) are the only criteria used to identify supposedly pre-existing opportunities (or non-opportunities)," which is a serious distortion of our argument because we never posit that losses are the only criteria used to identify supposedly pre-existing nonopportunities. ABMW seem to have missed 
our discussion of the indeterminacy-of-failure thesis: "when looking backward at instances of failure, we cannot typically determine whether an opportunity was absent or simply unactualized" (R\&T: 426). The tautology critique also contradicts the definition of tautology: "Epistemically, every proposition that can be known to be true by purely logical reasoning is a tautology" (Cambridge Dictionary of Philosophy, 1999: 903), such as the statement "All bachelors are unmarried men." Contrary to ABMW, the assumption that "profits are caused by the prior existence of objective opportunities" or that "only preexisting objective opportunities lead to profits" is not a "tautological assumption," for the simple reason that it cannot be known to be true by logical reasoning alone (see also Dreben \& Floyd, 1991).

Moreover, ABWM seem to confuse assumption with definition (see Tsang, 2006; 2009 for a discussion of the nature of assumptions). We do not assume but "define entrepreneurial opportunity as the propensity of market demand to be actualized into profits through the introduction of novel products or services" (R\&T: 411). Since profitability is a defining characteristic of entrepreneurial opportunities, a profitable outcome suggests the existence of the opportunity in question. It is somewhat like saying that a HIV-positive blood test result indicates HIV infection. There is nothing tautological here. Relatedly, we do not claim that profits "prove that opportunities are always objective" (\#). The thesis that opportunities exist is not provable empirically, but stems from meta-theoretical reflection (R\&T: 416; Kirzner, 1997). Profits may only prove the existence of concrete opportunities in specific regions of the economic landscape.

\section{Anti-realist Critiques}

In R\&T (412-413) we stress that (critical) realism presupposes social constructionism and only rejects its strong versions (see also Kwan \& Tsang, 2001). It is therefore perplexing that ABMW (\#) argue that realism does not offer a suitable philosophical platform because it 
allegedly fails to distinguish between physical "stuff" (like mountains and planets) and social "stuff" (like money and planetariums). We suspect that ABMW make this criticism because they inadvertently confuse two meanings of independence associated with the term "objectivity," viz. independence from society vis-à-vis independence from individual agents. Social reality is dependent on social agents but independent of any particular agent (Gorski, 2013: 666). Accordingly, we do not say that opportunities are objective because they exist autonomously from society in the ways that mountains do (Searle, 1995). Opportunities are objective in the sense that they exist independently from any given entrepreneur.

Furthermore, ABMW claim that the Popperian (Popper, 1990) underpinnings of our analysis commit us to "an extreme variant of the realist position" according to which "the opportunity to profit from teleportation machines-right now-is just as real as Apple's opportunity to continue selling iPhone 6 model phones" (\#). This version of realism is perfectly at odds with our realist position that has common sense as its point of departure (R\&T: 419-421; see in particular the moon travel example). It does not make much sense to talk about opportunities that can be actualized by ventures that are not even technologically possible.

\section{REALISM AS A PHILOSOPHY OF COMMON SENSE}

\section{Realism versus Empiricism}

Although Alvarez and Barney $(2010 ; 2013)$ correctly criticize the discovery approach for treating opportunities as physical entities, they incorrectly attribute this ontological fallacy to the discovery theory's alleged commitment to realist philosophy (Ramoglou, 2013). R\&T rectify this mistake by clarifying that the discovery approach in fact subscribes to empiricist philosophy. It is empiricism — not realism — which dictates that meaningful references to existence are confined to the observable (and inevitably actualized) domain of reality, nourishing effectively the idea that 
opportunities exist as measurable entities interacting causally with entrepreneurs (e.g., Baron, 2004; Davidsson, 2017). R\&T disentangle opportunities from empiricist influences by conceptualizing opportunities in a genuinely realist framework. Quite simply, realism says that prior to asking how to measure opportunities, we should first ask whether we can measure them. This matter can be addressed only through an ontological examination of the ways through which opportunities might be intelligibly said to exist (Lawson, 1997; Searle, 1998).

Unlike Alvarez and Barney, our ontological critique of the discovery approach is not preoccupied with the (occasional) treatment of opportunities as physical entities, but with the (routine) treatment of opportunities as actualized and empirically undiscovered entities. The discovery approach commits an ontological category mistake: there is nothing actualized in the world to be meaningfully named "entrepreneurial opportunity." New venture ideas (Davidsson, 2015), technological breakthroughs (Shane, 2003), regulatory and political changes (Shane, 2012), price information (Kaish \& Gilad, 1991), innovation opportunities (Cohen \& Winn, 2007) or venture opportunities (Shook, Priem, \& McGee, 2003) are not entrepreneurial opportunities.

Entrepreneurs may habitually talk about opportunities as something immediately observable and knowable. Yet they also know that opportunities do not exist as such. When an entrepreneur says, "I sense an opportunity to introduce a new widget" (Wood, 2017: 23), she does not mean that the opportunity lies in the introduction of the new widget itself. What she means is that the introduction of the widget is a means of profiting (or achieving some other goal). Entrepreneurs are (pre-theoretically) aware of those distinctions. They know that the opportunity to venture is not tantamount to the opportunity to succeed (McMullen, 2015: 660; R\&T: 422). However, we frequently overlook that when entrepreneurs say, "I see an opportunity in doing X," what they mean is "I see an opportunity to succeed by means of doing X." 
The ontological category of "opportunity" is that of propensity, referring to the conditions of possibility necessary for the successful realization of the ends (such as profits or growth) that motivate action. More precisely, profit opportunities essentially exist as the unobservable desires that can drive observable consuming behaviors of novel products or services (R\&T: 413, 416). Realism affords a suitable philosophical platform for accommodating these commonsensical understandings, because - contrary to naïve empiricist ontologies - it acknowledges that reality is irreducible to its actualized manifestations (Bhaskar, 1978).

B\&K launch an epistemological assault against our approach by framing realism as a bold philosophy: "how do critical realists motivate their bold claims about independent and ontologically real existence of causal mechanisms and entities operating on various levels (and by implication of opportunities-as-market-demand-propensities)?” (\#). Empiricist and idealist philosophies alike tend to develop philosophical systems without considering consistency with common sense—often precisely due to a profound distrust towards ordinary folks' understandings. As an intellectual counterforce, realism was fundamentally motivated as a philosophy of common sense (Bhaskar, 2016; Lawson, 2003; Searle, 1998). Realism endeavors to systematically organize and theoretically articulate the ontological commitments presupposed by competent human action. Indeed, everyday actions presuppose belief in independently existing and causally powerful mechanisms and propensities. As a simple example, when our PC does not operate properly, we do not throw it away on a whim. We simply know that there might be real causes hindering it from manifesting very real technological powers.

\section{Ontology versus Epistemology}

If there is nothing bold about our theorization of "opportunities-as-market-demandpropensities," what makes B\&K assert otherwise is their empiricist stance that reduces 
knowledge to statements about the empirically observable (Bhaskar, 1978). Philosophical extremities aside, in our non-academic moments we know that the observable is a subset of the real. ${ }^{1}$ In the context of opportunities, it would be unreasonable to say that an entrepreneur who claims that she has found an opportunity in unexploited market demand is making a bold ontological claim simply because the claim is about unobservables. Her claim might be bold only in the epistemological sense of being overconfident about the existence of the opportunity.

Also, by no means do we claim that "opportunities-as-market-demand-propensities can be known to exist, ex post as well as ex ante" (B\&K: \#). We know that opportunities exist. But this is a higher-order kind of knowledge that does not translate into spatiotemporally concrete knowledge of opportunities. We know that opportunities exist in the abstract ontological sense in which we know that undiscovered archeological artefacts do.

\section{AGAINST PHILOSOPHICAL EXTREMITIES}

\section{Objectivity of Opportunities}

We do not maintain that opportunities exist "out there" in the sense that they exist independently from society and similarly to mountains (ABMW: \#). They exist objectively in the sense that the market conditions necessary for the realization of profits predate entrepreneurial action. This implies that opportunities will not cease existence in the absence of such action. More importantly, it means that market conditions pre-determine which ventures can succeed.

Contrary to ABMW's contentions, the objectivist perspective is firmly grounded in the social world. In fact, it is the thesis that "opportunities do not exist independent of entrepreneurs" (Alvarez \& Barney, 2007: 13) that inadvertently trivializes how real socioeconomic structures condition the limits to the possible. If for the subjectivist perspective the only leader is the

\footnotetext{
${ }^{1}$ Even though this kind of knowledge cannot be proved empirically, it is provable philosophically. See for example Bhaskar's (1978: 30-35) analysis of the ontological presuppositions guiding the practice of experimental scientists.
} 
entrepreneur, the objectivist approach converges with Schumpeter (1983: 21) in that "the real leader is the consumer." It is consumers (along with other market and institutional forces) that determine whether a venture can succeed (see also F\&K: \#; McMullen \& Dimov, 2013). Yes, entrepreneurs lead the actualization process and can often intervene to affect market outcomes favorably. There are nevertheless limits to what an entrepreneur can achieve. When venturing in the domain of nonopportunity, an entrepreneur is doomed to fail—regardless the effort invested.

\section{The Explanatory Value of the Independence Attribute}

F\&K (\#) question "the explanatory value of talking about opportunities independent of the entrepreneur's beliefs and actions." Opportunities are conditions of possibility. If those conditions are not independent of the beliefs and actions of entrepreneurs, we commit the fallacy of "social atomism", (Knight, 1921). Accordingly, if the limits to the possible are malleable and not predetermined by society, we cannot but fall for the idealist philosophy of possibilism, according to which "nothing we imagine is absolutely impossible" (Hume, 1985: 81).

This strong idealist temperament encourages an unqualified pro-action bias (R\&T: 429). It further compels us to fall for extraordinary entrepreneurial qualities in order to ontologically account for the possibility of successful outcomes. Without commitment to the objectivity of opportunities, there is no (logically consistent) way of avoiding the conclusion that opportunities must be "willed into existence by savvy entrepreneurs" (Santos \& Eisenhardt, 2009: 664). In effect, entrepreneurship is (quasi-superstitiously) treated as "worldmaking" (Sarasvathy, 2012) and successful entrepreneurs emerge as the absolute masters of the economic universe. By contrast, the acknowledgment of independently existing opportunities relaxes the disposition to

\footnotetext{
${ }^{2}$ According to Knight's (1921: 77-78) articulation of this fallacy: "there is no exercise of constraint over any individual by another individual or by 'society' ... Every member of society is to act as an individual only, in entire independence of all other persons. To complete his independence he must be free from social wants, prejudices, preferences, or repulsions."
} 
idolize highly successful entrepreneurs, by recognizing that they might have simply actualized a pre-existing market opportunity (R\&T: 427). Mark Zuckerberg need not be regarded as a truly extraordinary individual who single-handedly created the Facebook empire. The related opportunity was waiting to be actualized independently of the particular entrepreneur who happened to actualize it. Likewise, unsuccessful entrepreneurs might have simply been unlucky to venture in the domain of nonopportunity. They need not belong to an inferior genre of economic actors lacking requisite "worldmaking powers."

\section{Possibilism versus Common Sense}

$\mathrm{B} \& \mathrm{~K}$ frame our perspective as deterministic. This is perplexing because we have forcefully rejected determinism by explaining that the mere existence of opportunities does not determine their actualization (R\&T: 418). The recognition of the limits to the possible associated with our defense of the objectivity of opportunity is not a defense of determinism. Rather, it is a rejection of the equally flawed doctrine of possibilism. Entrepreneurs operate in open systems where time surely matters (R\&T: 422-424): new windows of opportunity open all the time. However, we also warn against treating opportunities synonymously with "shared opportunity vision" (B\&K: \#): opportunity visions do not always have a real counterpart in (spatiotemporally-concrete) socioeconomic structures. In fact, the rejection of possibilism is a vindication of common sense. People typically have no difficulties coming up with business ideas. Yet as opposed to the idealist philosophical tendency of naming wanderings of the mind as “opportunity recognition," they are less inclined to trust their imagination as an unconditional guide into the possible (Searle, 1995; 1998): "entrepreneurs are arguably better attuned to the realist intuition that the realm of the naturally possible is a subset of the thinkable" (R\&T: 421). 
ABMW (\#) protest that their brand of opportunity creation is not as philosophically extreme, because it acknowledges the determining role of markets. We frame Alvarez and Barney $(2007 ; 2010)$ as possibilist, because we intend to engage with the most internally consistent and meaningful interpretation of their writings (Davidson, 1984: 183-198). Ironically, if their subjectivist approach does not subscribe to philosophical possibilism, it is inconsistent; or, even worse, does not even qualify as wrong.

\section{NOT EVEN WRONG: THE VERBAL ABUSES OF THE CREATION VIEW}

Our disagreement with the subjectivist thesis that "there is no pre-existing market to be analyzed and penetrated" (Korsgaard, 2011: 673) and "markets have to be invented, fabricated, constructed" (Sarasvathy, 2003: 308) is based on philosophical grounds. Possibilism is a philosophically extreme expression of the idealist mindset, but it does make sense. By contrast, the creation view of opportunities is often defended on grounds that are not even wrong, because they are essentially wordplay. To say that entrepreneurs create opportunities when they create products is to abuse the word "opportunity," and illicitly treat linguistic innovations as original theoretical angles (Ramoglou \& Zyglidopoulos, 2015: 74-75). To the extent that ABMW's creation view does not subscribe to the subjectivist perspective criticized above, it boils down to similar innovations. It does not advance a rival theoretical perspective, but fundamentally rests upon questionable linguistic practices (Davidsson, 2015: 680) (see also Crawford et al., 2016).

Ostensibly, ABMW appear to radically diverge from the R\&T conceptualization of opportunities. On closer inspection, however, the ABMW conceptualization appears to be consistent with the objectivist perspective: opportunities exist as "market imperfections" (\#). ${ }^{3}$

\footnotetext{
${ }^{3}$ ABMW (\#) suggest that opportunities exist in competitive imperfections in product (or factor) markets and that entrepreneurs who exploit them through a more efficient reallocation of assets can generate wealth. This view of opportunities actually resonates with ours. The concept "market imperfections" can be more directly stated as the propensity to generate wealth through the introduction of novel products that the market will embrace.
} 
The impression of incompatible theoretical viewpoints is due to the unnecessary use of the word "opportunity" when describing creative processes of wealth generation. There is no reason to say that "entrepreneurs can be successful in discovering or creating opportunities, but fail to act to exploit them" (\#), when what is created are new products. When entrepreneurs "introduce new products or reposition existing products" (\#), they do not create opportunities. It is perplexing to say that the new products are themselves the opportunities that entrepreneurs "then exploit to create wealth" (\#). This is especially the case given that we can simply say that creative activities are the means of exploiting possibly existing profit opportunities. After all, if an entrepreneur says that creating product $\mathrm{X}$ is an opportunity, she does not mean that she perceives the opportunity in creative deeds per se. Rather, she means that there is an opportunity to fulfil her goals by means of creating X. Similarly, there is no reason to say that opportunities are formed and abandoned when referring to the formation and abandonment of ventures (ABMW: \#).

Another source of confusion lies in the questionable use of philosophical jargon. No doubt, social reality is fundamentally socially constructed and institutions exist as ontologically subjective entities (Searle, 1995). However, it doesn't make much sense to say that opportunities themselves exist as "socially constructed" (Alvarez \& Barney, 2007: 15), "mind-dependent" (Alvarez et al., 2014: 228) or "ontologically subjective" phenomena (ABMW: \#). When people consume, they do not socially construct or institutionalize an additional layer of "opportunity." It is in the very acts of consumption that opportunities are actualized (if profits are generated). In short, when the "opportunities are created" part of the dilemma does not translate into the philosophically extreme view of possibilism, it boils down to questionable linguistic practices.

\section{RESPECTING THE LIMITS TO THE KNOWABLE}


ABMW criticize us for not offering empirical implications for researching opportunities themselves. This criticism, however, dogmatically assumes that all meaningful references to reality must have measurable implications (Alvarez, et al., 2014: 228). Similarly, in response to B\&K's complaint about the "practical irrelevance of propensities" (\#), we answer that there is nothing more practical than developing sound theoretical understandings of the world (Suddaby, 2014). In turn, such fundamental forms of understanding have the very practical implication of reorienting academic disciplines toward more realistic (and scientific) avenues (Lawson, 2003). More specifically, the centrality of uncertainty highlighted by realist meta-theory has concrete implications for theory, research, pedagogy and public policy (see R\&T: 424-430).

More crucially, however, appreciating the limits to the knowable protects our research from straying into blind alleys and our theorizing from conclusions with unwarranted certainty. If opportunities exist as propensities, they are not "empirically tractable" (B\&K: \#). We ought to accept their empirical elusiveness and limit empirical inquiries into what can be meaningfully studied. ${ }^{4}$ Accordingly, we should stop naming "opportunities" the (discovered or created) means of exploiting possibly existing opportunities or the beliefs-about-opportunities (e.g., Shane, et al., 2010). To do so is to treat possibilities as facts and encourage a naïve view of enterprise according to which what we (subjectively) think is also (objectively) possible.

\section{CONCLUSION}

Looking back, our paper was motivated by the fact that both the discovery and the creation approaches have fatal flaws. Most strikingly, both approaches talk paradoxically about

\footnotetext{
${ }^{4}$ It does not follow that "empirically tractable social mechanisms" (B\&K: \#) cannot be studied as part of the actualization processes. Nor does it follow that there are no meaningful empirical questions (e.g., about the ways entrepreneurs make sense of failure and success, [R\&T: 427-428]); or that we cannot help entrepreneurs improve their judgment regarding the possible reality of imagined opportunities (R\&T: 428-429; Dimov, 2016; McMullen, 2015). It only follows that we should stop thinking about opportunities as entities lending themselves to the construction of predictive theory (R\&T: 429-430; Dimov, 2016) (see also Ramoglou \& Tsang, 2017).
} 
the discovery or creation of opportunities prior to the realization of successful outcomes (see also McMullen, 2015). The creation view, as popularized by Alvarez, Barney, and their colleagues, has another major defect. Its fundamental premise is that "opportunities do not exist until entrepreneurs create them through a process of enactment" (Alvarez, Barney \& Anderson, 2013: 307) (see also Alvarez \& Barney, 2007: 15; Alvarez et al., 2014: 228). This is a universal statement supposedly describing all opportunities, similar to the statement "All swans are white." The premise contradicts "the opportunity to profit through the production of T-shirts and aprons with the 'Je suis Charlie' slogan (translation: 'I am Charlie') following the terrorist attack at Charlie Hebdo" (R\&T: 415). The opportunity itself (viz. the desire to protest against fundamentalist terrorism and simultaneously defend the freedom of the press) was obviously not created by those who produced these goods. Just like the existence of a non-white swan falsifies the statement "All swans are white," the opportunity associated with the terrorist attack falsifies the fundamental premise on which this approach is based, and thus overturns it. ABWM are silent with respect to this flaw highlighted in R\&T. Contradicting their universal statement, ABWM state that "opportunities endogenously created by entrepreneurs are just as legitimate an object of study as opportunities formed by exogenous shocks to a market or industry" (\#). One way to eliminate this self-contradiction is to abandon the universal statement and concede that some entrepreneurial opportunities are created whereas others aren't. Then ABMW face the uphill task of clearly distinguishing between these two types of opportunities, delineating their relationship, as well as coping with the fatal flaws associated with the discovery perspective.

Since ABMW (\#) distance themselves from the view that all entrepreneurial ventures are potential success stories, they essentially converge with the R\&T view of objectivity (in the sense outlined above). As such, an option out of the conundrum is to accept that all opportunities 
are agent-independent, though their exploitation is agent-dependent requiring varying levels of agency-intensity. After all, R\&T do not claim that all objectively existing opportunities exist as "ready-made" as in the Charlie Hebdo example. Entrepreneurs often have "to socially construct the conditions for consumer acceptance" (Suddaby, Bruton, \& Si, 2015: 3) for products that do not respond to active demand, such as the iPad. Still, such cases do not show that some opportunities are created. They only show that some opportunities are not readily exploitable, and that their actualization requires heightened levels of effort and/or resources (R\&T: 418). To do away with the objectivity stance is to accept that entrepreneurs can socially construct consumer acceptance for any new venture idea, no matter how stupid the idea may be.

If ABMW agree, there is no reason to keep talking about "creation opportunities," and preserve the dichotomous "objectively existing versus subjectively created" dilemma. If they disagree, they will need to justify their disagreement beyond misrepresenting realism, mislabeling the actualization view as tautological, or abusing the word "opportunity." Creative agency is unquestionably required for the exploitation of opportunities. Even in the Charlie Hebdo example, the precise ways of exploiting the opportunity was not readily apparent, and the design of the T-shirt or the choice of the slogan required creative imagination. However, to say that entrepreneurs create or form opportunities when they create products or form ventures, is to abuse the word "opportunity." There is no reason to say that opportunities are themselves created just because their actualization depends on entrepreneurs. This is not just semantics. Such language conflates the existence of opportunities with their exploitation, encouraging inadvertently an extreme worldview in which the limits to the possible are merely dictated by the limits of entrepreneurial imagination and creativity. Whenever opportunities really exist and are not only imagined, they do so as objective propensities to be creatively actualized. 


\section{REFERENCES}

Alvarez, S. A., \& Barney, J. B. 2007. Discovery and creation: Alternative theories of entrepreneurial action. Strategic Entrepreneurship Journal, 1: 11-26.

Alvarez, S. A., \& Barney, J. B. 2010. Entrepreneurship and epistemology: The philosophical underpinnings of the study of entrepreneurial opportunities. Academy of Management Annals, 4: 557-583.

Alvarez, S. A., \& Barney, J. B. 2013. Epistemology, opportunities, and entrepreneurship: Comments on Venkataraman et al. (2012) and Shane (2012). Academy of Management Review, 38: $154-157$.

Alvarez, S. A., Barney, J. B., \& Anderson, P. 2013. Forming and exploiting opportunities: The implications of discovery and creation processes for entrepreneurial and organizational research. Organization Science, 24: 301-317.

Alvarez, S. A., Barney, J. B., McBride, R., \& Wuebker, R. 2014. Realism in the study of entrepreneurship. Academy of Management Review, 39: 227-231.

Alvarez, S. A., Barney, J. B., McBride, R., \& Wuebker, R. 2017. On opportunities: Philosophical and empirical implications. Academy of Management Review, 42: \#.

Barney, J. B. 2001. Is the resource-based "view" a useful perspective for strategic management research? Yes. Academy of Management Review, 26: 41-56.

Baron, R. A. 2004. The cognitive perspective: A valuable tool for answering entrepreneurship's basic "why" questions. Journal of Business Venturing, 19: 221-239.

Berglund, H., \& Korsgaard, S. 2017. Opportunities, time, and mechanisms in entrepreneurship: On the practical irrelevance of propensities. Academy of Management Review, 42: \#.

Bhaskar, R. 1978. A realist theory of science. Hassocks, UK: Harvester Press.

Bhaskar, R. 2016. Enlightened common sense: The philosophy of critical realism. New York: Routledge.

Cambridge dictionary of philosophy (2nd Ed.). 1999. Cambridge: Cambridge University Press.

Cohen, B., \& Winn, M. I. 2007. Market imperfections, opportunity and sustainable entrepreneurship. Journal of Business Venturing, 22: 29-49.

Crawford, G. C., Dimov, D., \& McKelvey, B. 2016. Realism, empiricism, and fetishism in the study of entrepreneurship. Journal of Management Inquiry, 25: 168-170.

Davidson, D. 1984. Inquiries into truth and interpretation. Oxford: Clarendon Press. 
Davidsson, P. 2015. Entrepreneurial opportunities and the entrepreneurship nexus: A reconceptualization. Journal of Business Venturing, 30: 674-695.

Davidsson, P. 2017. Entrepreneurial opportunities as propensities: Do Ramoglou \& Tsang move the field forward? Journal of Business Venturing Insights, forthcoming.

Dimov, D. 2016. Toward a design science of entrepreneurship. Advances in Entrepreneurship, Firm Emergence and Growth, 18: 1-31.

Dreben, B., \& Floyd, J. 1991. Tautology: How not to use a word. Synthese, 87: 23-49.

Foss, N. J., \& Klein, P. G. 2017. Entrepreneurial discovery or creation? In search of the middle ground. Academy of Management Review, 42: \#.

Gorski, P. S. 2013. What is critical realism? And why should you care? Contemporary Sociology, 42: 658-670.

Hume, D. 1985. A treatise of human nature. London: Penguin.

Kaish, S., \& Gilad, B. 1991. Characteristics of opportunities search of entrepreneurs versus executives: Sources, interests, general alertness. Journal of Business Venturing, 6: 45-61.

Kirzner, I. M. 1979. Perception, opportunity and profit. Chicago: University of Chicago Press.

Kirzner, I. M. 1997. Entrepreneurial discovery and the competitive market process: An Austrian approach. Journal of Economic Literature, 35: 60-85.

Kirzner, I. M. 1999. Creativity and/or alertness. Review of Austrian Economics, 11: 5-17.

Knight, F. H. 1921. Risk, uncertainty and profit. Chicago: University of Chicago Press.

Korsgaard, S. 2011. Entrepreneurship as translation: Understanding entrepreneurial opportunities through actor-network theory. Entrepreneurship \& Regional Development, 23: 661-680.

Kwan, K.-M., \& Tsang, E. W. K. 2001. Realism and constructivism in strategy research: A critical realist response to Mir and Watson. Strategic Management Journal, 22: 1163-1168.

Lawson, T. 1997. Economics and reality. London: Routledge.

Lawson, T. 2003. Reorienting economics. London: Routledge.

McMullen, J. S. 2015. Entrepreneurial judgment as empathic accuracy: A sequential decisionmaking approach to entrepreneurial action. Journal of Institutional Economics, 11: 651-681.

McMullen, J. S., \& Dimov, D. 2013. Time and the entrepreneurial journey: The problems and 
promise of studying entrepreneurship as a process. Journal of Management Studies, 50: 14811512.

McMullen, J. S., \& Shepherd, D. A. 2006. Entrepreneurial action and the role of uncertainty in the theory of the entrepreneur. Academy of Management Review, 31: 132-152.

Popper, K. R. 1990. A world of propensities. Bristol, UK: Thoemmes Antiquarian Books.

Ramoglou, S. 2013. On the misuse of realism in the study of entrepreneurship. Academy of Management Review, 38: 463-465.

Ramoglou, S., \& Tsang, E. W. K. 2016. A realist perspective of entrepreneurship: Opportunities as propensities. Academy of Management Review, 41: 410-434.

Ramoglou, S., \& Tsang, E. W. K. 2017. Embracing the uncertainties of entrepreneurship and overcoming philosophical obstacles to scientific progress: A reply to Per Davidsson. Journal of Business Venturing Insights, forthcoming.

Ramoglou, S., \& Zyglidopoulos, S. 2015. The constructivist view of entrepreneurial opportunities: A critical analysis. Small Business Economics, 44: 71-78.

Santos, F. M., \& Eisenhardt, K. M. 2009. Constructing markets and shaping boundaries: Entrepreneurial power in nascent fields. Academy of Management Journal, 52: 643-671.

Sarasvathy, S. D. 2003. Constructing corridors to economic primitives: entrepreneurial opportunities as demand-side artefacts. In J. Butler (Ed.), Opportunity identification and entrepreneurial behavior: 291-312. Greenwich, CT: Information Age Publishing.

Sarasvathy, S. 2012. Worldmaking. Advances in Entrepreneurship, Firm Emergence and Growth, 14: 1-24.

Schumpeter, J. A. 1983. The theory of economic development: An inquiry into profits, capital, credit, interest, and the business cycle. New Brunswick, NJ: Transaction Publishers.

Searle, J. R. 1995. The construction of social reality. London: Penguin.

Searle, J. R. 1998. Mind, language and society: Philosophy in the real world. New York: Basil Books.

Shane, S. 2003. A general theory of entrepreneurship: The individual-opportunity nexus. Northampton, MA: Edward Elgar.

Shane, S. 2012. Reflections on the 2010 AMR Decade Award: Delivering on the promise of entrepreneurship as a field of research. Academy of Management Review, 37: 10-20.

Shane, S., Nicolaou, N., Cherkas, L., \& Spector, T. D., 2010. Do openness to experience and 
recognizing opportunities have the same genetic source? Human Resource Management, 49: 291-303.

Shane, S., \& Venkataraman, S. 2000. The promise of entrepreneurship as a field of research. Academy of Management Review, 25: 217-226.

Shook, C. L., Priem, R. L., \& McGee, J. E. 2003. Venture creation and the enterprising individual: A review and synthesis. Journal of Management, 29: 379-399.

Suddaby, R. 2014. Editor's comments: Why theory? Academy of Management Review, 39: 407411.

Suddaby, R., Bruton, G. D., \& Si, S. X. 2015. Entrepreneurship through a qualitative lens: Insights on the construction and/or discovery of entrepreneurial opportunity. Journal of Business Venturing, 30: 1-10.

Tsang, E. W. K. 2006. Behavioral assumptions and theory development: The case of transaction cost economics. Strategic Management Journal, 27: 999-1011.

Tsang, E. W. K. 2009. Assumptions, explanation, and prediction in marketing science: "It's the findings, stupid, not the assumptions.” Marketing Science, 28: 986-990.

Wood, M. S. 2017. Misgivings about dismantling the opportunity construct. Journal of Business Venturing Insights, 7: 21-25. 